\title{
Cantilever structure in modern construction
}

\author{
Elena Generalova ${ }^{1,{ }^{*}}$, Viktor Generalov ${ }^{1}$, and Anna Kuznetsova ${ }^{1}$ \\ ${ }^{1}$ Samara State Technical University, Institute of Architecture and Civil Engineering, \\ 194, Molodogvardeyskaya St, 443001, Samara, Russia
}

\begin{abstract}
This article discusses innovative ways of using cantilever structures in modern construction. It highlights that the unique design of cantilever structures pushes forward the physical possibilities of architecture and construction, challenges the attractive force and breaks stereotypes. The authors provide an analysis of the best worldwide experience of introducing the cantilever elements in the objects of different functional purposes. Unique engineering solutions with a cantilever span of over $20 \mathrm{~m}$ are paid special attention to. The paper considers the basic technologies, design systems, materials and testing techniques that make it possible to create "flying" structures. Peculiar features of using the cantilever structures in high-rise buildings and high-technology development of high-rise erection are described. Special attention is paid to the economic, safe and environmentally sound technology for the use of lightweight concrete slabs with void formers reducing the amount of concrete and the mass of slabs without losing strength. As a result, the paper describes the prospects for introducing the cantilever elements in modern construction and their functional use.
\end{abstract}

\section{Introduction}

A study of the objects of modern architecture and construction technologies used in the engineering and design systems has shown that at the conceptual and architectural stage the creative work of architects is increasingly related to the desire to use innovative design solutions. These solutions make such objects unique. In accordance with article 48, paragraph 2, of the Russian Urban Code, unique buildings and facilities can be referred to capital construction facilities if they have at least one of the following characteristics in their project documentation: 1 - height of over 100m; 2- span of over $100 \mathrm{~m}$; 3-cantilever of over $20 \mathrm{~m}$; 4 - the substructure of over $15 \mathrm{~m}$ below ground level. The purpose of this research is to study, analyze and identify the specific use of unique cantilever structures in modern buildings.

The first step is to deal with key concepts and terminology. A number of definitions of cantilever elements in architecture can be found in literature. Summarizing these definitions it can be said that a cantilever is a rigid structural element anchored at only one end to a (usually vertical) support from which it protrudes.

\footnotetext{
*Corresponding author: generalova-a@yandex.ru
} 
The larger the cantilever span the more complex calculations are required for calculating loads, selecting the design and the properties of materials. All of this, of course, increases the cost of such buildings and facilities. Despite of this fact, the cantilevers are actively used in modern facilities of different functional purpose [1-10]. Building cantilever structures helps to find solutions for various tasks, such as urban planning (the problem of the lack of space on the site with difficult terrain), aesthetics (designing an interesting and unusual façade), functional design (creating additional space with unique view characteristics), symbolic (forming a mass image that works as a landmark and an architectural symbol of a city), etc.

\section{Materials and Methods}

It should be noted that nowadays there is a great variety of cantilever architectural and structural elements of buildings that perform certain functional and aesthetic tasks. They can be classified as follows: type 1- a roof that is an element of the building that has enclosure and structural functions (the roof can be walkable); type 2-part of a building's volume of the height of one or more floors (from small oriel windows to great volumes of a building); type 3-open sites that protrude from a facade's flat area (balconies, terraces) and have different functions and equipment (see Fig.1).
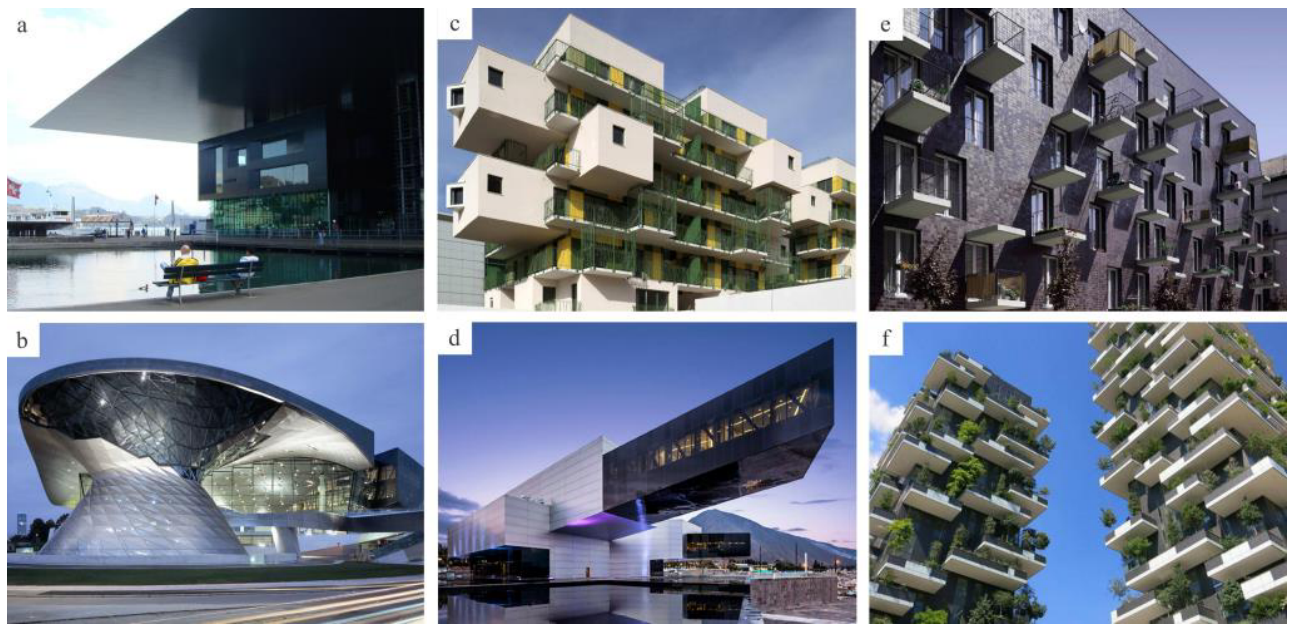

Fig. 1. (a) Lucerne Culture and Congress Centre (KKL), architect - Jean Nouvel, 2000, (b) BMW Welt, Munich, Germany, architects - Coop Himmelb(1)au, 2007, (c) 28 Social Housing, Paris, France, KOZ Architectes, 2010, (d) UNASUR General Secretary Headquarters in Quito, Ecuador, architect Diego Guayasamin, 2014, (e) Práter Street 30-32, architects - PLANT Atelier Peter Kis, Budapest, Hungary, 2007, (f) Bosco Verticale Torre, architects - Stefano Boeri Architetti, 2014.

The use of innovative technologies, materials and design systems enables to increase the application of cantilever structures. It allows choosing the best solutions for them and overcoming different risks. In this study the authors would like to highlight the modern designed capabilities of steel (metallic) and reinforced concrete cantilever structures in unique buildings that have won a visual victory over gravity.

\section{Results}

The paper considers in details the examples of the above mentioned classification. The Busan Cinema Center, located in the city of Busan (South Korea) is a unique architectural 
object completed in 2012. The building was designed by a cooperative architectural design firm Coop Himmelb(l)au, Austria. It is registered in the Guinness World Records for the «longest cantilever roof» (see Fig.2). The roof of the Busan Cinema Center features a cantilever that extends $85 \mathrm{~m}$ [11]. "Flying Roof" is $21 \mathrm{~m}$ above the ground. It relies on single cone-shaped column support - The Double Cone where the main entrance and a café are located. The structure of this cone is a spatial metallic structure consisting of horizontal rings connected by diagonal links.
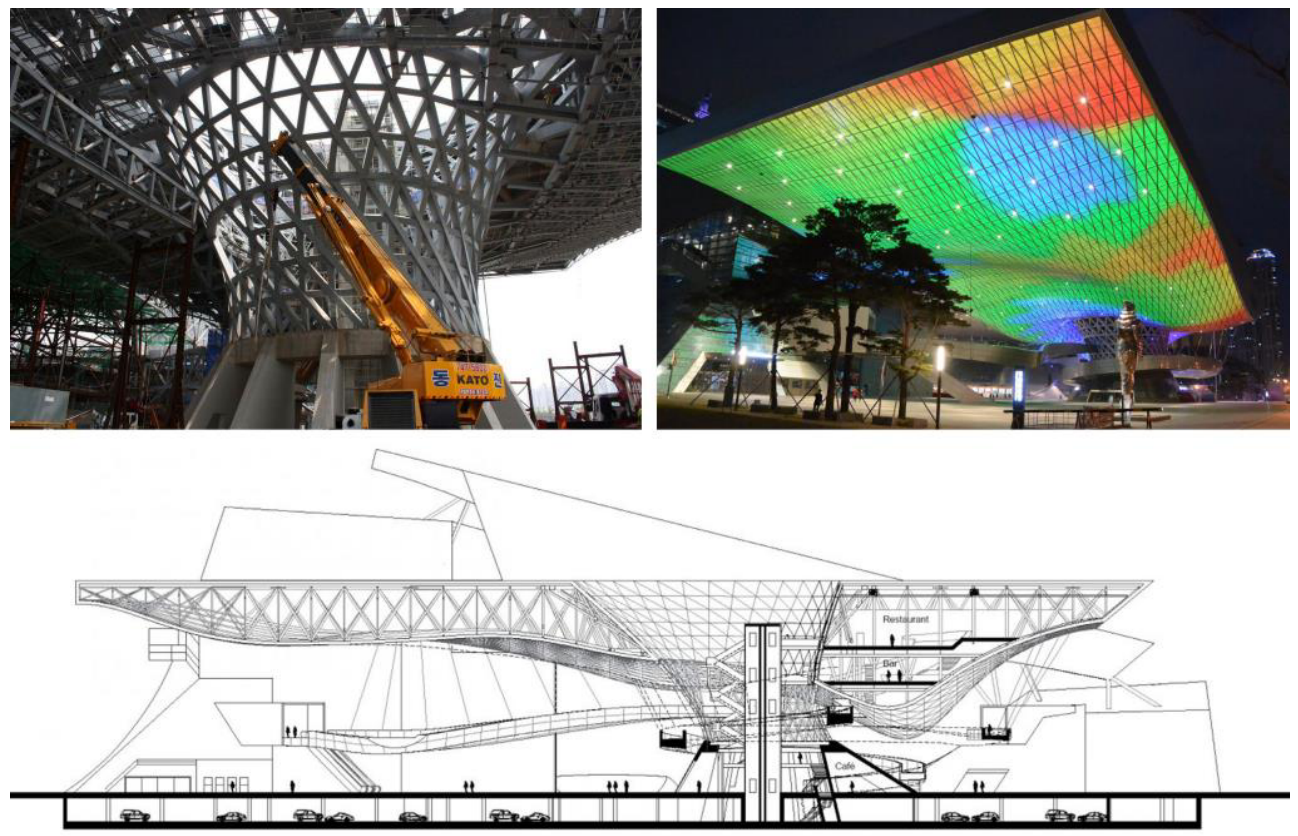

Fig. 2. Busan Cinema Center, Busan, South Korea, architects - Coop Himmelb(1)au, 2012 [12].

The giant roof is a metal space structure. Its upper surface is flat while the inner surface is of undulated shape. LED saturated outdoor roof elements act as a screen for light shows. The greater part of the metal framework was produced at factories and assembled at the construction site. The roof is anchored to The Double Cone by a structural element named «crown». This design project shows the reinterpretations of the roof as an integral architectural element that forms the system of interrelated open-architecture (the Urban Valley, the Red Carpet Zone, the Walk of Fame, the Memorial Court, the BIFF Canal Park, open cinema for 4000 people) and close-architecture (cinemas, theatres, studious, offices, restaurants, etc.) public spaces. The giant cantilever of the Busan Cinema Center shows not only contemporary capabilities of metal structures but also the new concept of forming the urban environment with hybrid functions.

Another example is «Marina Bay Sands» (Safdie Architects) that realizes the most courageous engineering, architectural and aesthetic fantasies and innovations (see Fig. 3). A distinctive feature of this complex is the unique engineering design of the public platform «Sands SkyPark» located at the height of $200 \mathrm{~m}$ (the 57th floor). It can house 3900 people. The platform of 1.2 hectares is $340 \mathrm{~m}$ length and maximum $40 \mathrm{~m}$ width. It combines three high-rise towers and is covered with a cantilever of $65 \mathrm{~m}$ which is one of the largest in the world. «Sands SkyPark» is a real tropical oasis with a large garden (250 trees and 650 plants), recreation areas, treadmills, restaurants and «Infinity Pool» that is the largest outdoor pool in the world, located at such a height (area-1396 m², length-150 m). One of the main attractions of this platform is the Sands SkyPark public observation deck located 
just within a 65-metre-long cantilever on the 57th floor. This is an example of creating vertical urban environment with high density. Urban functions that traditionally tend to land (areas, parks, basins, etc.) are actively developed in the high-rise on its walkable roof as a new type of public space.
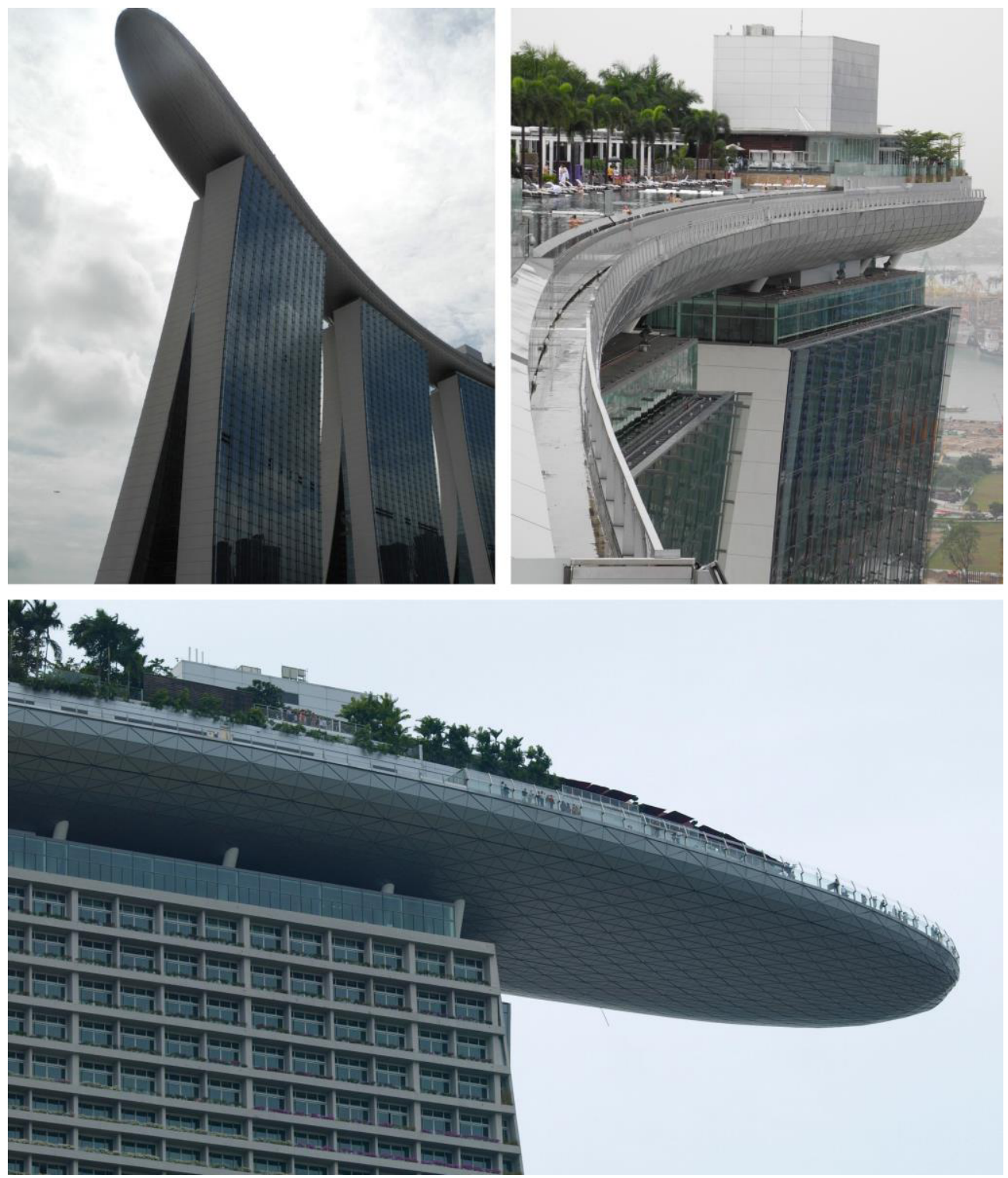

Fig. 3. Marina Bay Sands, Singapore, Safdie Architects, 2010.

To make this concept real a lot of engineering innovations had to be introduced: 1- wind load-the unique spatial metal structure of the platform consisting of mega trusses was designed taking into account the constant movement of the three towers because of wind, for this purpose special clearances and sliding elements with a range of up to $0.5 \mathrm{~m}$ were provided; 2 - load of the pool. The problem of introducing a large continuous infinity edge pool was solved by making three separate 50 -metre stainless steel shells united in a flexible singular whole; 3-assambly problem-the metal structure of the platform consists of 14 
separate sections which were produced at a factory and raised one by one to the top of the tower with hydraulic jacks and mounted into a single structure there (the largest sections are two box girders of $80 \mathrm{~m}$ long that are the base of the cantilever. It took 16 hours to lift them to the assembling position at $14 \mathrm{~m} / \mathrm{h}$; 4-the problem of resonance in the cantilever. One of the solutions to this problem is to use of a 5-ton dampener hidden inside the structure and suspended to the transverse beams at the end of the cantilever [13].

Advanced technologies, materials and constructive systems are tools that can lead not only to economic and efficient use of different resources, but also to a higher and innovative level of functional and architectural planning of a building. The analysis of the following object, Columbia University Medical and Graduate Education Building (CUMGEB) shows the peculiar features of using unusual public space «The Study Cascade» (see Fig. 4). "The Study Cascade» is developed vertically within 14 floors and consists of cantilevered volumes flowing into each other and creating spaces of different volume and function. The spaces are connected by stairs and ramps. A «porous» structure was created to facilitate the communication of students, teachers and the urban environment.
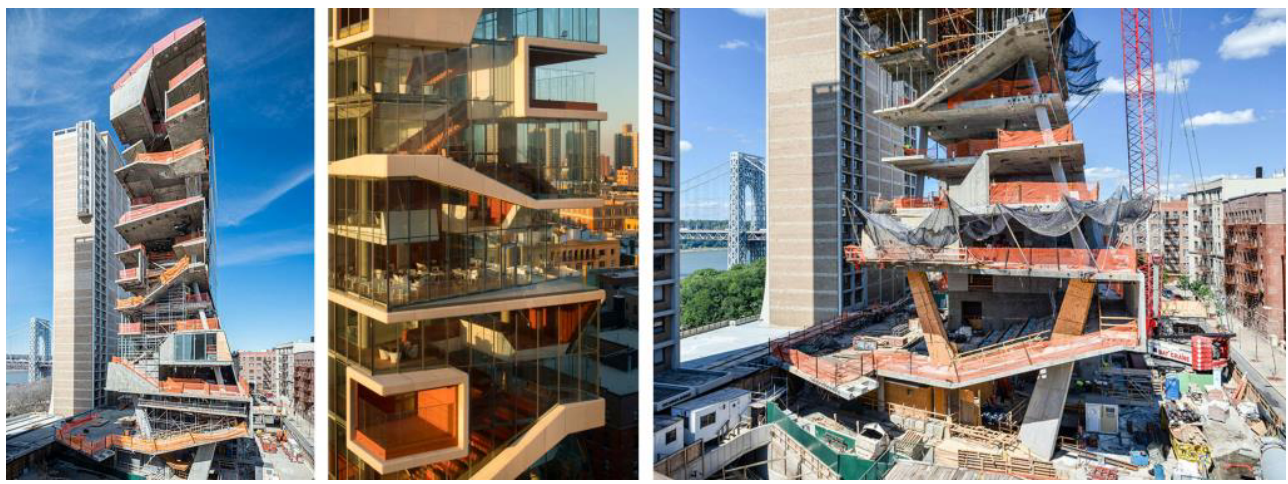

Fig. 4. Columbia University Medical and Graduate Education Building (CUMGEB), New York, United States, architects - Diller Scofidio + Renfro, 2016 [14].

The emphasis was made on vertical spatial links, which is against the traditional organization of horizontal communication institutions. It is to be noted that neither new materials nor new technologies were developed for this building. However, an integrated approach to architectural and design solutions, integration of forms and functions made it possible to optimize the existing developments. A post-tensioned concrete structure of high strength concrete, structural steel, high strength rebar and self-consolidating concrete was chosen for «The Study Cascade». Void formers were extensively used in the construction of concrete slabs.
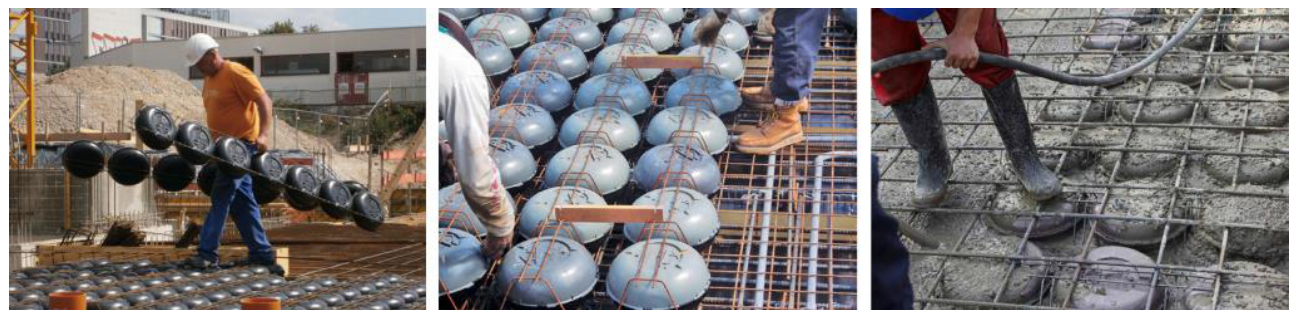

Fig. 5. Cobiax Technologies AG (a void former made from plastic, which takes the place of the solid concrete within the reinforced slab). 
The technology of reducing the use of concrete in slabs should be considered in details. The examples are the developments of the Canadian company «BubbleDeck» or the Swiss firm Cobiax Technologies AG (its products are manufactured in Russia by franchise company «Ecotechplaza», Moscow). The analogy of this product is the unremovable deck adapted to the Russian rules and regulations produced by OOO Sibforma (Novosibirsk). The common thing to these technologies is the use of plastic hollow void formers to fill reinforced slabs (see Fig5). As a result slabs lose up to 35\% of their mass but retain strength properties. The described technology is the ideal solution for floorings with spans and cantilevered concrete structures where large free space is needed when using a minimum number of columns.

\section{Discussion}

Having analyzed the unique buildings with introduced cantilever architectural and structural elements it can be concluded that their aesthetic and symbolic characteristics are subordinated to urban and functional planning tasks and are generally innovative solutions. Surely thanks to impressive appearance they have become visible and meaningful urban landmarks but it is much more important that they form a fresh approach to public urban space. Its main features are multifunctionality; protection from negative exposure to the weather; different functional use; the link to the interior space of a building; the ability to reproduce vertically; the creation of urban environment with high density. This is essential under the conditions of intense global urbanization when the search for new approaches to creating the urban living environment is becoming a vital issue.

\section{Conclusions}

In conclusion it should be pointed out that the considered architectural and engineering elements of the buildings are at the cutting-edge of scientific and technological progress and are a site for introducing not only advanced but experimental constructive systems, materials and technologies as well. All these things make these buildings unique. At the same time when considering the prospects of introducing cantilever elements in modern construction and taking into account extensive functional capabilities it is necessary to reflect on their mass use in urban environment at the level of standardized and harmonized typological and constructive structures.

\section{References}

1. V.P. Generalov, E.M. Generalova, Urban Construction and Architecture 4(21), 23-29 (2015) DOI 10.17673/Vestnik.2015.04.3

2. E.M. Generalova, V.P. Generalov, A.A. Kuznetsova, Procedia Engineering 153, $167-$ 172 (2016)

3. T.Y. Vavilova, N.D. Potienko, I.V. Zhdanova, Procedia Engineering 153, 938-943 (2016)

4. N.A. Ilyin, D.A. Panfilov, A.P. Shepelev, Panfilov, A.P. Shepelev, Urban Construction and Architecture 4(17), 98-106 (2014) DOI 10.17673/Vestnik.2014.02.14

5. A.Y. Zhigulina, N.G. Chumachenko, Urban Construction and Architecture 4(21), 9499 (2015) DOI 10.17673/Vestnik.2015.04.12

6. V.P. Generalov, E.M. Generalova, Urban Construction and Architecture 2(23), 85-90 (2016) DOI 10.17673/Vestnik.2016.02.16 
7. H.Y. Lee, Z.X. Hou, Procedia Engineering 14, 1089-1097 (2011)

8. N.X. Liu, X. Zhao, H.H. Sun, Y.M. Zheng, J.M. Ding, Procedia Engineering 14, $2503-$ 2510 (2011)

9. M. Balzannikov, V. Alpatov, I. Kholopov, A. Saharov, A. Lukin, MATEC Web of Conferences 73, 01012 (2016)

10. S.A. Mizuryaev, A.G. Chiknovorian, G.S. Solopova, R.V. Demidov, Procedia Engineering 153, 599-603 (2016)

11. E.M. Generalova, V.P. Generalov, Scientific Survey 11, 46-51 (2015)

12. Busan Cinema Center / Busan International Film Festival. [Online]. Available: http://www.coop-himmelblau.at/architecture/projects/busan-cinema-center [Accessed: Apr. 3, 2017]

13. M. Safdie, CTBUH Journal I, 12-17 (2011)

14. Roy and Diana Vagelos Education Center / Diller Scofidio + Renfro. [Online]. Available: http://www.archdaily.com/793971/roy-and-diana-vagelos-education-centerdiller-scofidio-plus-renfro [Accessed: Apr. 3, 2017] 